\title{
Demiryolu Aracı Disk Balatalarının Tasarımında Yüksek Sıcaklığın Neden Olduğu Fren Zayıflama Probleminin Belirlenmesi İçin Sonlu Elemanlar Yöntemi Yaklaşımı
}

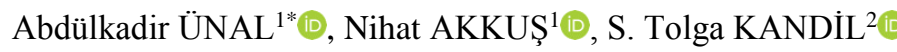 \\ ${ }^{1}$ Marmara Üniversitesi, Fen Bilimleri Enstitüsü, Mekatronik Mühendisliği Bölümü, İstanbul, Türkiye \\ ${ }^{2}$ Ylldı Teknik Üniversitesi, Mühendislik Fakültesi, Makine Mühendisliği Bölümü, İstanbul, Türkiye \\ *abdulkadir.unal@turasas.gov.tr
}

(Alınış/Received: 24.11.2021, Kabul/Accepted: 06.01.2022, Yayımlama/Published: 31.01.2022)

Öz: Demiryolu aracı fren sürtünme elemanlarında, uzun süre fren yapılmasına bağlı olarak disk ve balata yüzeyinde sıcaklık artışı meydana gelmektedir. Artan sıcaklıkla birlikte fren performansını düşüren ve zayıflama (fading) olarak adlandırılan önemli bir problem ortaya çıkmaktadır. Sürtünme elamanı tasarımcıları, zayıflama problemini öngörebilmek amacıyla tasarım aşamalarında genelde dinamometre gibi deneysel test yöntemleri kullanmaktadırlar. $\mathrm{Bu}$ tarz deneysel yöntemler kabul görmüş güvenilir yöntemler olsa da zaman ve maliyet açısından dezavantajlıdır. Bu çalışma, fren sürtünme elemanı tasarımlarında zayıflama problemine karşı deneysel yöntemler yerine bilgisayar destekli sonlu elemanlar yöntemlerini kullanarak termal öngörüde bulunulmasını sağlamayı ve böylece zamandan ve maliyetten tasarruf elde edilmesini amaçlamaktadır. Bu amaçla geleneksel deney yöntemleri yerine sonlu elemanlar yöntemi ile modelleme yapılarak termal analiz yapılmış ve bu analiz sonuçları gerçek demiryolu testleri ile doğrulanmıştır. Gerçek demiryolu testlerinde diskte oluşan maksimum sıcaklıklar K tipi bir termokupl yardımıyla ölçülmüş ve elde edilen sonuçlar analiz sonuçları ile karşılaştırılmıştır. Karşılaş̧ırıma sonucunda sonlu elemanlar yöntemi sonucunda elde edilen değerlerin gerçek demiryolu testleri sonucunda elde edilen değerler ile büyük oranda örtüştüğü gözlemlenmiştir. Aracın maksimum hızı olan $140 \mathrm{~km} / \mathrm{h}$ hızda yapılan frenleme sonucunda deneysel olarak ölçülen maksimum ortalama sicaklık $384{ }^{\circ} \mathrm{C}$ iken simülasyon sonucunda ölçülen maksimum sıcaklık $400{ }^{\circ} \mathrm{C}$ 'dir. Elde edilen veriler zayıflama problemini tespit etmek için sonlu elemanlar yönteminin fren sürtünme elemanı tasarımında kullanılabileceğini ve böylece zamandan ve maliyetten tasarruf sağlanabileceğini göstermektedir.

Anahtar kelimeler: Fren zayıflamas1, Disk balata, Termal FEA

\section{Finite Element Method Approach Against to Brake Fading Problem in Railway Vehicle Brake Friction Element Design}

\begin{abstract}
Temperature increase occurs on the disc and pad surface due to long-term braking. With increasing temperature, an important problem called fading arises, which reduces brake performance. Friction element designers generally use experimental test methods such as dynamometers in the design stages in order to predict the fading problem. Although such experimental methods are accepted and reliable methods, they are disadvantageous in terms of time and cost. This study aims to provide thermal prediction by using computer-aided finite element methods instead of experimental methods against the fading problem in brake friction element designs and thus saving time and cost. For this purpose, thermal analysis was performed by modeling with the finite element method instead of traditional test methods, and these analysis results were confirmed by real railway tests. In real railway tests, the maximum temperatures occurring in the disc were measured with the help of a K-type thermocouple, and the results obtained were compared with the results of the analysis. As a result of the comparison, it has been observed that the values obtained as a result of the finite element method largely overlap with the values obtained as a result of the real railway tests. As a result of braking at $140 \mathrm{~km} / \mathrm{h}$, which is the maximum speed of the vehicle, the experimentally measured maximum average temperature is $384{ }^{\circ} \mathrm{C}$, while the maximum temperature measured as a result of the simulation is $400^{\circ} \mathrm{C}$. The obtained data has revealed that the FEA can be used in brake friction element design to detect the attenuation problem, thus saving time and cost.
\end{abstract}

Atıf için/Cite as: A. Unal, N. Akkus, S. T. Kandil, "Demiryolu aracı disk balatalarının tasarımında yüksek sıcaklığın neden olduğu fren zayıflama probleminin belirlenmesi için sonlu elemanlar yöntemi yaklaşımı," Demiryolu Mühendisliği, no. 15, pp. 134-144, Jan. 2022. doi: 10.47072/demiryolu. 1027982 
Keywords: Fading, Disc pad, Thermal FEA

\section{Giriş}

Mekanik fren sistemi, aracın sahip olduğu kinetik enerjinin 1sı enerjisine dönüşmesi prensibiyle çalışır. Sürtünme elemanlarının birbirine sürtünmesi ile oluşan 1sı çevreye yayılır [1]. Araç fren sistemi tasarımı aşamasında mekanik özelliklerin yanı sıra sistemin ısıl özelliklerinin de dikkate alınması gerekmektedir [2]. Frenleme sırasında yüksek sıcaklık, frenin zayıflamasına, erken aşınmaya, yatak arızasına, disk ve balata yüzeyinde termal çatlaklara ve termal olarak uyarılan titreşime neden olabilir [3]. Bu nedenle fren tasarımında temel konu, fren ömrü ve etkinliğinin tahmininde anahtar faktör olan hem ortalama hem de yerel sıcaklıkları ölçmek veya tahmin etmektir [4].

Geleneksel olarak, fren testleri için birçok deneysel yöntem kullanılmaktadır. Gerçek disk frenleri simüle etmek için, sürtünme değerlendirme tarama testi (Friction Assessment and Screening Test), azaltılmış ölçekli dinamometre yöntemi, chase makinesi testleri, pin-on-disk testleri, krauss testleri ve gerçek boyutlu dinamometre yöntemi gibi çeşitli deneysel yöntemler bulunmaktadır [5].

Sürtünme değerlendirme tarama testi (FAST), sürtünme malzemesinin (etkililik, toparlanma, hız hassasiyeti ve aşınma özellikleri) taraması için bir kalite kontrol testi olarak kabul edilir [6]. Chase makinesi, bir hava basıncı sistemi ile tamburun iç çapına karşı yüklenen kare sürtünme malzemesine sahip dönen bir tamburdan oluşur. Chase makinesi ile sürtünme ve aşınma verileri elde edilebilir [7]. Pin on disk yöntemi, önceden belirlenmiş bir dizi koşul altında bir alt numune olarak dönen bir diske karșı pim șeklinde bir numuneyi içerir [8]. Krauss test makineleri tam boyutlu fren mekanizmalarını test etmeyi mümkün kılar. Bir fren mekanizmasındaki yükleme koşulları, bir DC motor kullanılarak simüle edilir [9]. Tam boyutlu dinamometreler, genel olarak demiryolu aracının fren performansını test etmek için yaygın olarak kullanılmaktadır. Fren dinamometresi, trenin fren karakteristiğini simüle etmek için tasarlanmış, çoğaltılabilen ve deney nesnesini analiz etmeye ve karşılaştırmaya yardımcı olan verileri kaydetme işlevine sahiptir. Fren dinamometresi ayrıca fren sistemini geliştirmek ve test etmek için kullanılır [10].

$\mathrm{Bu}$ test yöntemlerinin yanı sıra, simülasyon tekniklerinin gelişmesiyle birlikte, günümüzde araç üreticileri fiziksel testleri sanal testlerle kısmen veya tamamen değiştirmeyi araştırmaktadır [11]. Fren diski ve balatasının aşınma durumunun değişmesine karşılık gelen fren performansı düşüşü nedeniyle, yüksek güçlü disk frenin sürtünme ve aşınma analizi tüm dünyada bir araştırma noktası haline gelmiştir [12]. Sürtünme çiftlerinin sergileyecekleri davranışları tahmin edebilecek bir simülasyon aracı fren endüstrilerinde anahtar bir role sahip olabilir [13]. Disk frenleri için bir çok simülasyon çalışması yapılmıştır [14].

Narayana vd. [15] fren diski tipi malzemesini termomekanik özelliklere göre belirlemek amaciyla sonlu elemanlar yöntemini kullanmıştır. Nirmala vd. [16] fren diski seçimi için sonlu elemanlar analizi yöntemini kullanarak bir simülasyon geliştirmiş ve farklı diskleri yapısal ve termal olarak incelemiştir. Belhocine [17] frenleme aşamasında sonlu elemanlar yöntemini kullanarak otomobil disk freninin termomekanik davranışının bir çalışmasını sunmuştur. Gautam vd. [18] bir diski modelleyerek daha uzun ömür için yapısal olarak incelemiştir. Liu vd. [19] kampanalı fren sistemini sonlu elemanlar yöntemi ile inceleyerek sağ ve sol blok balataların simetrik çalışıp çalışmadığını araştırmıştır. Goo [20] sonlu elemanlar yöntemini kullanarak disk ve balata arasında temas basınc1 ve termo-elastik davranışlar üzerine çalışmıştır. Zhang vd. [21] frenleme sırasındaki aşınmanın değişim eğilimini incelemiş ve fren yükünün ve ilk frenleme hızının aşınma üzerindeki etkilerini sonlu elemanlar yöntemi yardımıyla analiz etmiştir. Gabriele vd. [22] bir fren sisteminin sürtünme katsayısını simüle etmek için sonlu elemanlar analizi yaklaşımını kullanmıştır. Gurumoorthy vd. [23] fren balatası aşınmasını simüle etmek, aşınmaya dayalı ömür hesaplaması 
yapmak ve havadaki aşınma parçacıklarını tahmin etmek için hesaplama yöntemleri geliştirmeye odaklanmıştır. Rashid vd. [24] termo-mekanik sonlu elamanlar analizi kullanarak disk üzerindeki aşınma geçmişini incelemiştir. Sonuçlar, aşınma dikkate alındığında, her yeni fren çevrimi için disk üzerindeki farklı sıcaklık dağılımlarının elde edildiğini göstermiştir.

$\mathrm{Bu}$ çalışmada pnömatik fren sistemi kullanan bir tren setinin sürtünme elemanlarında meydana gelen termal dağılımlar sonlu elemanlar yöntemi kullanılarak analiz edilmiş ve analiz sonuçlarını doğrulmak amaciyla gerçek demiryolu testleri yapılmıştır. Bu testler sonucunda sonlu elamanlar yöntemi ile gerçek demiryolu testleri sonucunda elde edilen veriler birbirleriyle karşılaştırılmıştır. Simülasyon sonuçları ve yol testi sonuçlarının birbirini büyük oranda doğruladığı sonucuna varılmıştır. Balata tasarımında simülasyon yöntemlerinin çoğalması zaman ve maliyet açısından tasarruf sağlarken daha etkin ve güvenilir tasarımların ortaya çıkmasına neden olacaktır.

\section{Metot}

$\mathrm{Bu}$ çalışmada tren setlerinin sürtünme çiftlerinde meydana gelen sıcaklık artışı sonlu elemanlar yöntemi kullanılarak analiz edilmiş ve analiz sonuçları gerçek yol testleri ile doğrulanmıştır.

Modellemesi yapılan ve testler sırasında kullanılan tren seti 4 adet araçtan meydana gelmektedir. $\mathrm{Bu}$ araçlar SKA1, OA1, OA2 ve SKA2 araçlarıdır. SKA1 sürücü kabinli motorlu araç, OA1 çekilen orta araç, OA2 motorlu orta araç, SKA2 sürücü kabinli çekilen araçtır. Tren setine ait konfigürasyon Şekil 1'de gösterilmiştir. Tren setine ait temel sayısal değerler Tablo 1'de verilmiştir.

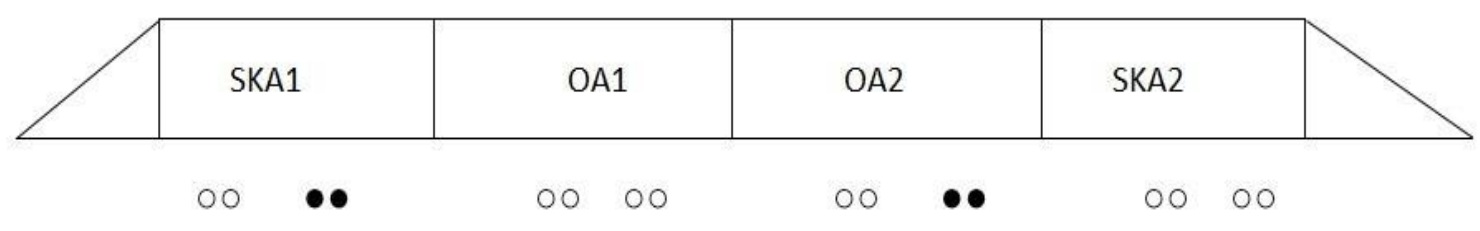

Şekil 1. Tren seti konfigürasyonu (o o tahriksiz boji, • • tahrikli boji)

Tablo 1. Araç bilgileri (veriler araç üreticisinden sağlanmıştır)

\begin{tabular}{cc}
\hline Araç Bilgileri & Değerler \\
\hline Boji Başına Disk Sayısı & 4 \\
Teker Çapı & $920 \mathrm{~mm}$ \\
Disk Çapı & $660 \mathrm{~mm}$ \\
Disk Malzemesi & Döküm Çelik \\
Araç Maksimum Hızı & $140 \mathrm{~km} / \mathrm{h}$ \\
Acil Frende Eşdeğer Yavaşlama İvmesi & $1,19 \mathrm{~m} / \mathrm{s}^{2}$ \\
Dinamik Sürtünme Katsayısı & 0,40 \\
Disk başına döner kütleler dâhil fren ağırı̆̆ğı & $8735 \mathrm{~kg}$ \\
\hline
\end{tabular}

\subsection{Sonlu elemanlar analizi}

Modellemesi yapılan balatalar UIC 541- 3'e göre üretilen UIC 200 (200 cm² yüzey alanlı) tipi kompozit disk balatalardır. Balatalar diskin sağ ve solunda konumlanan balata çiftlerinden meydana gelmektedir. Disk ise $660 \mathrm{~mm}$ çapında ve dökme çelikten üretilmiştir.

Disk ve balatanın üç boyutlu modeli SOLIDWORKS 2020.SP2 paket programı kullanılarak çizilmiştir. Sonlu elemanlar analizi için genel amaçlı bir sonlu eleman programı olan Ansys Ls- 
Dyna V4.5.18 paket programı kulanılmıştır. Ls-Dyna açık zaman entegrasyonu kullanan doğrusal olmayan dinamik modellerde sıkça kullanılmaktadır.

Sonlu elemanlar analizi yaklaşımında implicit (kapalı) ve explicit (açık) yöntemler vardır. Bu iki yaklaşım arasındaki temel fark hız ve ivmedir. İmpilicit algoritma, ti zamanında denklemin ilk çözümünün bilgisini varsayar ve ti +1 zamanında denklemin çözümünü hesaplar. Explicit, implicit prosedüründen farklı olarak merkezi fark yöntemini kullanır. Bu sonuç olarak, ivme matrisinin bir yaklaşımı için başlangıç noktasının ti zamanı olduğu anlamına gelir. Bu çalışmada sistemin anlık durumundan belirli bir zaman sonraki durumu hesaplandığından explicit yöntem kullanılmışır. Disk ve balatanın mesh yapısı Şekil 2'de verilmektedir.


Şekil 2. Fren diski ve balata çiftlerinin mesh yapısı

Disk ve balatanın üç boyutlu modeli Solidworks paket programı kullanılarak çizilmiştir. Sonlu elemanlar analizi için genel amaçlı bir sonlu eleman programı olan Ansys Ls-Dyna V4.5.18 paket programı kulanılmıştır. Ls-Dyna açık zaman entegrasyonu kullanan doğrusal olmayan dinamik modellerde sıkça kullanılmaktadır.

Modellenen disk ve balata 69564 adet elemandan ve 95814 adet düğüm noktasından oluşmaktadır.

Balata üzerine gelen kuvvetler $29920 \mathrm{~N}$ olarak balata yüzeylerine tanımlanmıştır. Bu kuvvet haritalandırılmış basınç sensörü kullanılarak deneysel olarak ölçülmüştür. Ölçümü yapabilmek için haritalandırılmış basınç sensörü disk ve balata arasına yerleştirilmekte ve elde edilen değer bir bilgisayar yardımıyla Şekil 3 'te verildiği şekilde haritalandırılmış şekilde okunmaktadır.

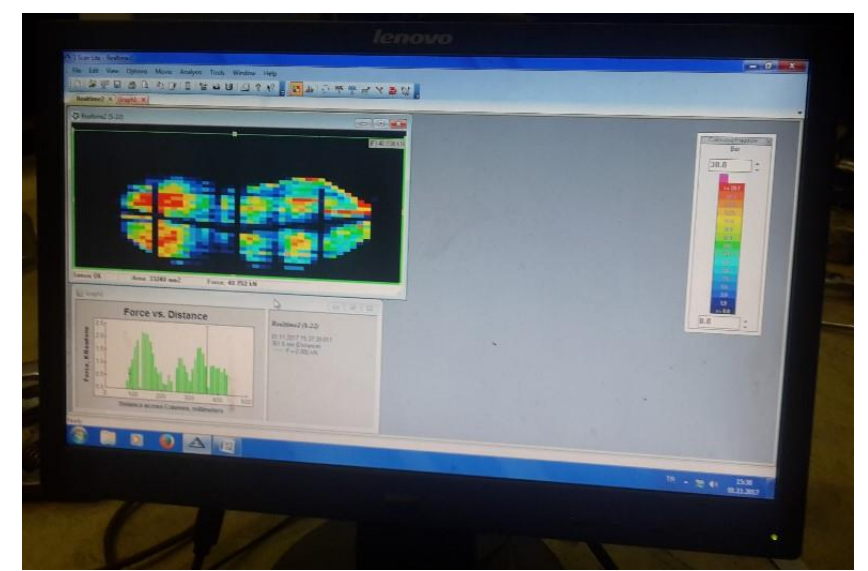

Şekil 3. Haritalandırılmış basınç sensörü yardımıyla disk üzerine gelen kuvvetlerin belirlenmesi 


\subsection{Yol testleri}

Yol testleri için TÜRASAŞ tarafından üretilen ve TCDD Taşımacılık AŞ filosunda bulunan 15400 tipi dizel tren setleri kullanılmıştır. Testler Yüksek Hızlı Tren Hattında MithatpaşaKöseköy, Köseköy-Mithatpaşa istasyonları arasında yapılmıştır. Yüksek Hızlı Tren Hattının kullanılabilmesi amacıyla TCDD'den izin alınarak yol kiralanmıştır.

Frenleme neticesinde diskte meydana gelen sıcaklık artışı K tipi termokupl kullanılarak ölçülmüş ve ölçülen sıcaklıklar TQC marka data logger ile kayıt altına alınmıştır. Diske monte edilen termokupl ve veri kaydedici Şekil 4'te gösterilmiştir.

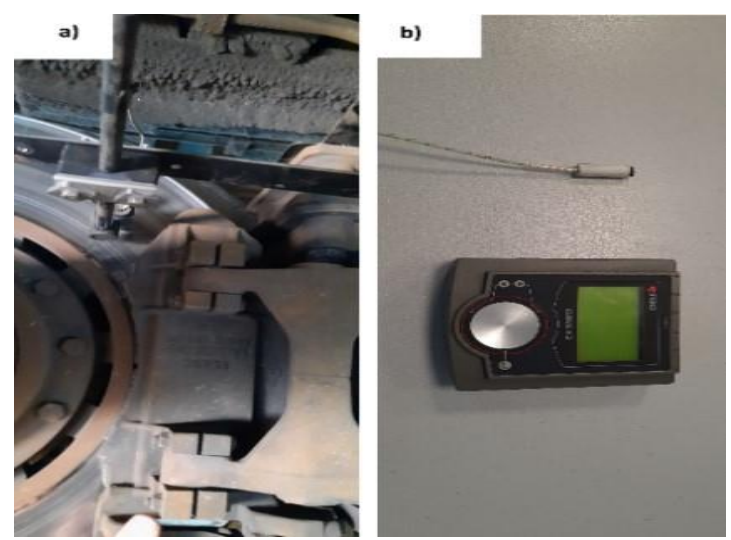

Şekil 4. a) Sıcaklık sensörünün montaj edilmiş hali, b) Test sırasında kullanılan veri kaydedici ve termokupl

Testler $140 \mathrm{~km} / \mathrm{h}$ hizda makinist ana kontrol kolunun EB (acil fren) konumuna getirilerek yapılmıştır. Ana kontrol kolunun EB konumuna getirilmesiyle birlikte retarder kapanmakta ve sürtünme elemanları sayesinde tren seti durmaktadır.

Aracın hız verileri aks başlarında bulunan hız sensörü vasıtasıyla ölçülmüştür. Hız sensörü Şekil 5'te verilmiştir. Hız sensörü, fiziksel temas olmaksızın bir dönen dişlinin hızını algılamak ve böylece aks hızını tespit etmek için aks kutusuna bağlı olacak şekilde tasarlanmıştır. Algılama cihazı ve amplifikatör elektroniği, alüminyum bir muhafaza içinde hava geçirmez şekilde kapatılmıştır. Ünite, verilen geometride dönen bir ferromanyetik dişli çarkın dişlerini ve boşluklarını algılar. Manyetik alan değişiklikleri, algılama cihazı tarafından elektrik sinyallerine dönüştürülür.

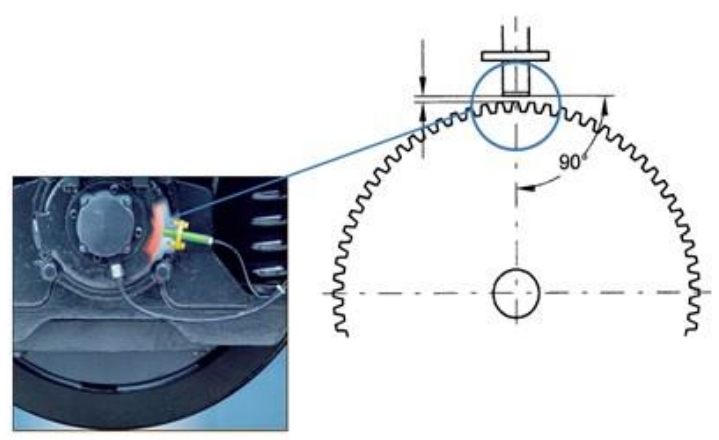

Şekil 5. H1z sensörünün kurulumu 
Eğim ve kurp dirençlerinin test sonuçlarını etkilememesi için frenlemeler eğimsiz ve kurpsuz aliyman yollarda yapılmıştır. Her frenleme sonrasında disk ve balatanın soğuması için yeterince beklenilmiştir.

\section{Bulgular}

\subsection{Sonlu elemanlar analizi sonuçları}

Frenleme yapıldığı andaki araç hızı $140 \mathrm{~km} / \mathrm{h}(38888 \mathrm{~mm} / \mathrm{s})$ ve tekerlek yarıçapı $460 \mathrm{~mm}$ olduğu için diske $84 \mathrm{rad} / \mathrm{s}$ başlangıç hızı uygulanmıştır. Diske uygulanan fren balatası kuvveti Şekil 6'da verilmiştir. Balatanın diske uyguladığı maksimum kuvvet 29920 N'dur.

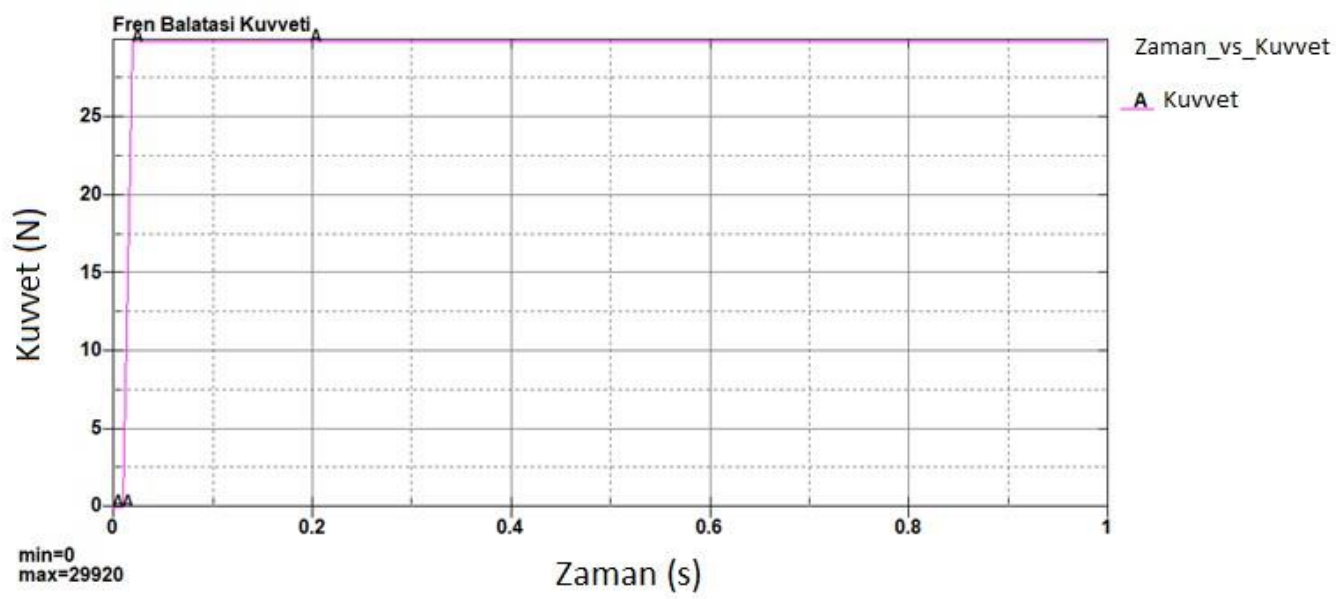

Şekil 6. Balatadan diske uygulanan frenleme kuvveti

$30 \mathrm{~km} / \mathrm{h}$ hız için yapılan termal analiz sonucunda, sürtünmeden ve dinamik kuvvetten dolayı açığa çıkan enerjinin, disk ve balata üzerindeki sıcaklık dağılımları Şekil 7'de verilmiştir. Farklı hızlarda yapılan frenleme sonucu oluşan maksimum sıcaklık değerleri Tablo 2'de verilmiştir. Tablo 2'de verilen hız aralıkları aracın fren test protokolüne göre seçilmiştir.

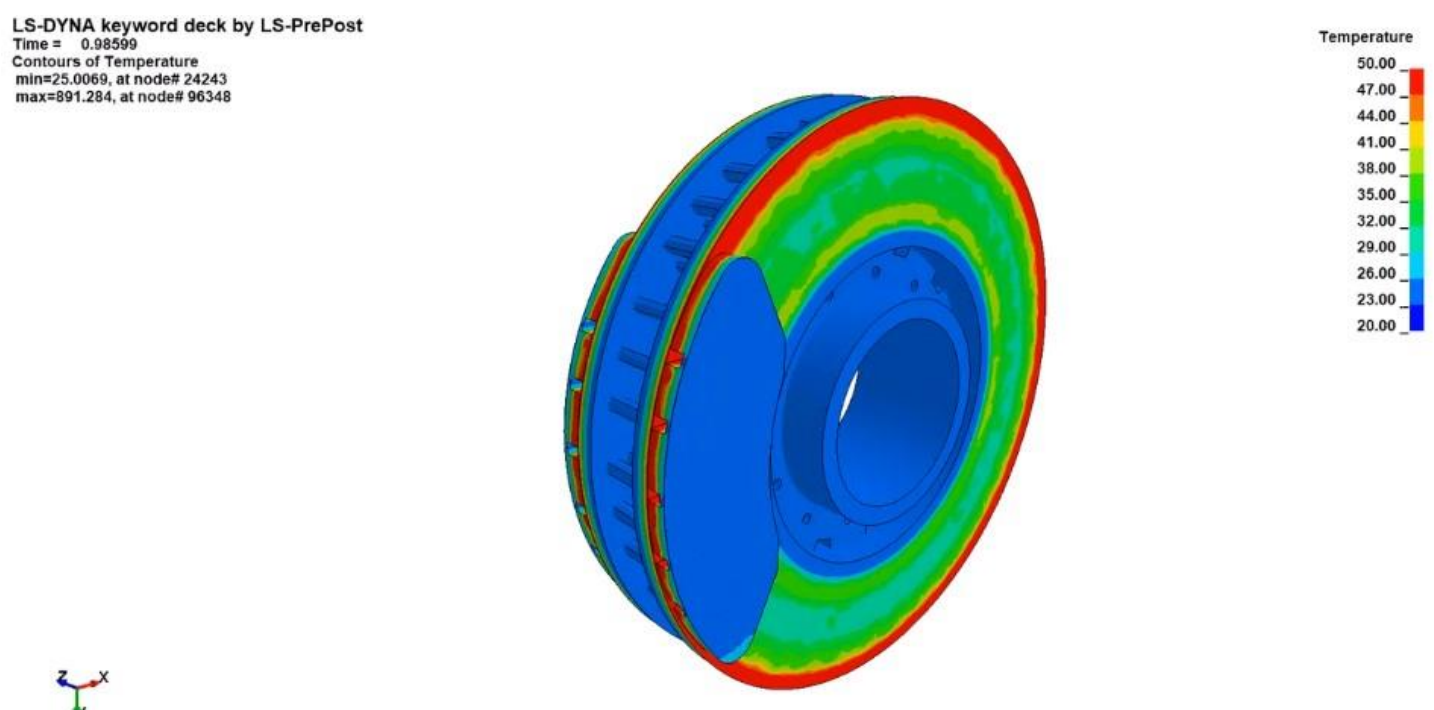

Şekil 7. Disk ve balata üzerinde meydana gelen sıcaklık dağılımı 
Tablo 2. FEA sonuçları

\begin{tabular}{cc}
\hline Frenleme Yapıldığ Andaki Hız $(\mathrm{km} / \mathrm{h})$ & Maksimum Sıcaklık $\left({ }^{\circ} \mathrm{C}\right)$ \\
\hline 30 & 50 \\
80 & 200 \\
100 & 250 \\
120 & 350 \\
140 & 400 \\
\hline
\end{tabular}

\subsection{Yol testi sonuçları}

Yol testlerinde önce düşük hızlarda daha sonra yüksek hızlarda seri frenler yapılmıştır. Seri frenlemenin yapılmasının nedeni balataların yeni olması nedeniyle balata yüzeyinin alıştırılmasını (bedding) sağlamaktır. Yataklama işlemi yapıldıktan sonra $80 \mathrm{~km} / \mathrm{h}, 100 \mathrm{~km} / \mathrm{h}, 120$ $\mathrm{km} / \mathrm{h}$ ve $140 \mathrm{~km} / \mathrm{h}$ hızlarda frenlemeler yapılmış ve maksimum disk sicaklıkları kayıt altına alınmıştır. Disk sıcaklıklarının doğruluğunu teyit etmek amacıyla her hızda en az 5 frenleme yapılmıştır.

Yaklaşık $30 \mathrm{~km} / \mathrm{h}$ hızdan tam durana kadar ölçülen maksimum sicaklık değerleri Tablo 3 'te verilmiştir. $30 \mathrm{~km} / \mathrm{h}$ hıza en yakın yakalanan hızlar değerlendirmeye alınmıştır.

Tablo 3. Yaklaşık $30 \mathrm{~km} / \mathrm{h}$ hızda ölçülen maksimum sıcaklıklar ve simülasyon sonuçlarının karşılaştırılması

\begin{tabular}{ccc}
\hline Frenleme Anındaki Hızları $(\mathrm{km} / \mathrm{h})$ & $\begin{array}{c}\text { Disk Yüzey Sicaklığ } 1\left({ }^{\circ} \mathrm{C}\right) \\
\text { (Deneysel) }\end{array}$ & $\begin{array}{c}\text { Disk Yüzey Sıcaklı̆̆ } 1\left({ }^{\circ} \mathrm{C}\right) \\
\text { (Simülasyon) }\end{array}$ \\
\hline 30,26 & 53,2 & \\
30,73 & 56,9 & 50 \\
30,42 & 52,6 & \\
30,16 & 52,8 & 50 \\
30,24 & 54,3 & 5,96 \\
Ortalama & 53,9 & \\
\hline
\end{tabular}

Yaklaşı $80 \mathrm{~km} / \mathrm{h}$ hızdan tam durana kadar ölçülen sıcaklık değerleri Tablo 4 'te verilmiştir. 80 $\mathrm{km} / \mathrm{h}$ hıza en yakın yakalanan hızlar değerlendirmeye alınmıştır.

Tablo 4. Yaklaşık 80 km/h hızda ölçülen maksimum sıcaklıklar ve simülasyon sonuçlarının karşılaştırılması

\begin{tabular}{ccc}
\hline Frenleme Anındaki Hizlar $(\mathrm{km} / \mathrm{h})$ & $\begin{array}{c}\text { Disk Yüzey Sicaklığ }\left({ }^{\circ} \mathrm{C}\right) \\
\text { (Deneysel) }\end{array}$ & $\begin{array}{c}\text { Disk Yüzey Sicaklı̆̆ }\left({ }^{\circ} \mathrm{C}\right) \\
\text { (Simülasyon) }\end{array}$ \\
\hline $80,53 \mathrm{~km} / \mathrm{h}$ & 178,4 & \\
$79,87 \mathrm{~km} / \mathrm{h}$ & 184 & 200 \\
$80,26 \mathrm{~km} / \mathrm{h}$ & 191,5 & \\
$80,72 \mathrm{~km} / \mathrm{h}$ & 192,1 & \\
$80,13 \mathrm{~km} / \mathrm{h}$ & 188,9 & 200 \\
Ortalama & 186,98 & \\
\hline
\end{tabular}

Yaklaşık $100 \mathrm{~km} / \mathrm{h}$ hızdan tam durana kadar ölçülen sıcaklık değerleri Tablo 4'te verilmiştir. 100 $\mathrm{km} / \mathrm{h}$ hıza en yakın yakalanan hızlar değerlendirmeye alınmıştır. 
Tablo 5. Yaklaşık 100 km/h hızda ölçülen maksimum sıcaklık değerleri ve simülasyon sonuçlarının karşılaştırılması

\begin{tabular}{ccc}
\hline Frenleme Anındaki Hızları $(\mathrm{km} / \mathrm{h})$ & $\begin{array}{c}\text { Disk Yüzey Sıcaklığ }\left({ }^{\circ} \mathrm{C}\right) \\
(\text { Deneysel) }\end{array}$ & $\begin{array}{c}\text { Disk Yüzey Sicaklı̆g } 1\left({ }^{\circ} \mathrm{C}\right) \\
\text { (Simülasyon) }\end{array}$ \\
\hline 99,82 & 239,4 & \\
99 & 241,3 & 250 \\
99 & 245 & \\
101 & 248,6 & 250 \\
100,29 & 246 & 2506 \\
Ortalama & 244,06 & \\
\hline
\end{tabular}

Yaklaşık $120 \mathrm{~km} / \mathrm{h}$ hızdan tam durana kadar ölçülen sıcaklık değerleri Tablo 6'da verilmiştir. 120 $\mathrm{km} / \mathrm{h}$ hıza en yakın yakalanan hızlar değerlendirmeye alınmıştır.

Tablo 6. Yaklaşık 120 km/h hızda ölçülen maksimum sıcaklık değerleri ve simülasyon sonuçlarının karşılaştırılması

\begin{tabular}{ccc}
\hline Frenleme Anındaki Hızları $(\mathrm{km} / \mathrm{h})$ & $\begin{array}{c}\text { Disk Yüzey Sicaklığ }\left({ }^{\circ} \mathrm{C}\right) \\
\text { (Deneysel) }\end{array}$ & $\begin{array}{c}\text { Disk Yüzey Sicaklığı }\left({ }^{\circ} \mathrm{C}\right) \\
\text { (Simülasyon) }\end{array}$ \\
\hline 120,45 & 341,6 & \\
120,03 & 348,9 & 350 \\
120,48 & 338,5 & \\
119,52 & 346,7 & 350 \\
120,33 & 345 & 34,14 \\
Ortalama & 344,14 & \\
\hline
\end{tabular}

Yaklaşı 140 km/h hızdan durana kadar ölçülen sıcaklık değerleri Tablo 7'de verilmiştir. 140 $\mathrm{km} / \mathrm{h}$ hıza en yakın yakalanan hızlar değerlendirmeye alınmıştır.

Tablo 7. Yaklaşık 140 km/h hızda ölçülen maksimum sıcaklık değerleri ve simülasyon sonuçlarının karşılaştırılması

\begin{tabular}{ccc}
\hline Frenleme Anındaki Hızları $(\mathrm{km} / \mathrm{h})$ & $\begin{array}{c}\text { Disk Yüzey Sıcaklığı }\left({ }^{\circ} \mathrm{C}\right) \\
(\text { Deneysel) }\end{array}$ & $\begin{array}{c}\text { Disk Yüzey Sicaklı̆̆ }\left({ }^{\circ} \mathrm{C}\right) \\
\text { (Simülasyon) }\end{array}$ \\
\hline 139,99 & 378,4 & \\
139,85 & 382,6 & 400 \\
139,98 & 376,8 & \\
138,66 & 390,2 & \\
140,11 & 396,3 & 400 \\
Ortalama & 384,86 & \\
\hline
\end{tabular}

\section{Sonuç}

Bu çalışma diskli fren balatalarında her iki temas yüzeyi arasındaki termal dağılımı simüle etmek için bir yaklaşım sunmaktadır. Bu amaçla balata ve diskte oluşan sıcaklık değişimini bilgisayar ile simüle etmek amaciyla sonlu elemanlar yöntemi kullanılarak bir model oluşturulmuş ve modelin doğruluğunu kanıtlamak amacıyla gerçek demiryolu şartlarında disk sıcaklığı farklı hızlarda yapılan frenleme sonucunda ölçülmüş̧ür. Yol testleri ve model sonuçları Şekil 8'de verilen grafikte karşılaştırılmıştır.

Şekil 8'de verilen grafikten de görüleceği üzere sonlu elemanlar analizi sonuçları ile yol testi sonuçları birbirini doğrulamaktadır. Bu sonuçlara göre sonlu elemanlar yönteminin fren sürtünme elemanı tasarımında kullanılabileceği ve böylece zamandan ve test maliyetlerinden tasarruf elde edilebileceği sonucuna varılmıştır. Ancak geleneksel test yöntemleri fren sürtünme elemanı tasarımcılarına sıcaklık bilgisinin yanı sıra aşınma ve sürtünme katsayısı değerleri üzerinde de bilgiler sunmaktadır. Bu yüzden yapılan araştırma aşınma ve sürtünme katsayısı değişimlerini de içerecek şekilde geliştirilmeli ve bu değerler üzerinde kapsamlı bir tahmin sunmalıdır. 


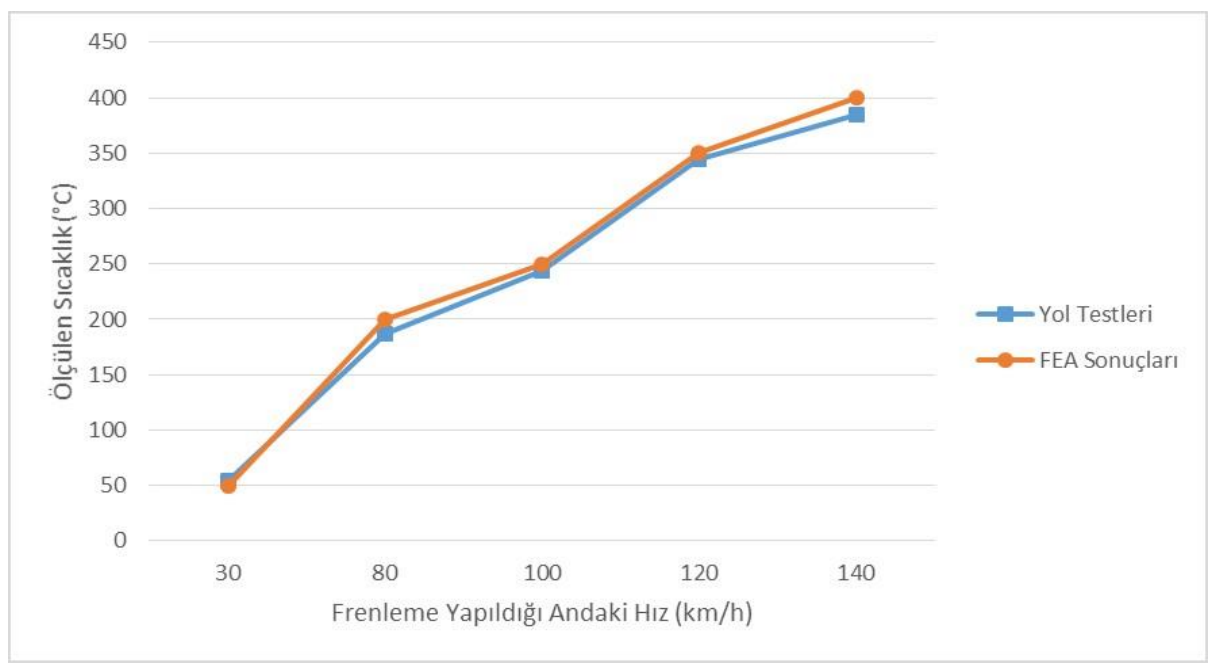

Şekil 8. FEA sonucu elde edilen sıcaklık değerleri ile yol testi sonucu elde edilen sıcaklık değerlerinin karşıllaştırması

\section{Teşekkür}

Bu çalışmayı 1007 KAMAG 118G039 numaralı proje kapsamında destekleyen Türkiye Bilimsel ve Teknolojik Araştırma Kurumu'na (TÜBİTAK) teşekkür ederiz. Bu çalışmada bahsi geçen görüşler sadece yazarlara aittir ve başka hiçbir organizasyon ve kişiyi temsil etmemektedir.

\section{Kaynakça}

[1] L. Abebe, R. Nallamothu, K. Subrahmanyam, S. Nallanothu, A. Nallamothu, "Thermal Analysis of Disc Brake Made of Different Materials," SSRG International Journal of Mechanical Engineering, vol. 3(6), pp. 5-9, 2016.

[2] P. Milenkovic, S. Jovanovic, A. Jankovic, M. Milovanovic, N. Vitosevic, M. Djordjevic, M. Raiceviv, "The Influence of Brake Pads Thermal Conductivity on Passnager Car Brake System Efficiency," Thermal Science, vol. 14, pp. 221-230, 2010, doi: 10.2298/TSCI100505016M

[3] F. Talati, S. Jalalifar, "Analysis of heat conduction in a disc brake system," Heat Mass Transfer, vol. 45, pp. 1047-1059, 2009, doi: 10.1007/s00231-009-0476-y

[4] T. Piatkowski, H. Polakowski, M. Kastek, P. Baranowski, K. Damaziak, J. Malachowski, L. Mazurkiewicz, "Thermal measurement of brake pad linning surfaces during the braking process," The international societyc for optical engineering, 2012, doi: 10.1117/12.918391

[5] A. Sinha, G. Ischia, C. Menapace, S. Gialanella, "Experimental characterization protocols for wearproducts for wear products from disc brake materials," Atmosphere, vol. 11, 2020, doi: doi:10.3390/atmos11101102

[6] M. Kchaou, A. Sellami, J. Fajoui, R. Kus, R. Elleuch, F. Jacquemin, "Tribological performance characterization of brake friction materials: What test? What coefficient of friction?," Journal of Engineering Tribology, vol. 233, pp. 214-225, 2019, doi: 10.1177/1350650118764167

[7] P. Blau, "Compositions, functions, and testing of friction brake materials and their additives," OAK ridge national laboratory, 2001.

[8] N. Stoica, A. Petrescu, A. Tudor, A. Predescu, "Tribological properties of the disc brake friction couple materials in the range of small and very small speeds," 13th International Conference on Tribology, 2017, doi:10.1088/1757-899X/174/1/012019

[9] T. Singh, A. Patnaik, "Friction braking performance of nanofilled hybrid fiber reinforced phenolic composites: Influence of nanoclay and carbon nanotubes," World Scientific, vol. 8, no. 3, 2013, doi:10.1142/S1793292013500525

[10] M. Kim, J. Kim, B. Goo, "Comparative studies of the tread brake dynamometer between dry and wet conditions," Selected topics in system science and simulation in engineering, pp. 479-483, 2010.

[11] A. Vdovin, G. Gael, "Aerodynamic and thermal modelling of disc brakes challenges and limitations," Energies, vol. 13 (1), pp. 1-12, 2020, doi: 10.3390/en13010203 
[12] S. Zhang, Q. Hao, Y. Liu, L. Jin, "Simulation study on friction and wear law of brake pad in highpower disc brake," Mathematical Problems in Engineering, vol. 2019, pp. 1-15, 2019, doi: $10.1155 / 2019 / 6250694$

[13] G. Riva, "A methodology to simulate automotive disc brake tribology and emissions," Doctoral Thesis in Machine Design KTH Royal Institute of Technology Stockholm, Sweden, 2020

[14]H. Cho, C. D. Cho, "A study of thermal and mechanical behavior for the optimal design of automotive disc brakes," Automobile Engineering, vol. 222, pp. 894-915, 2008.

[15] K. Narayana, G. U. Rao, D. Simhachalam, B. Nagarju, "Finite Element Analysis of Solid and Ventilated Disc Brake," International Journal of Science and Research (IJSR), vol. 3, no. 9, pp. 875882, 2014.

[16]D. Nirmala, C. Kiran, "Otimized Design and Static, Dynamic Analysis of Disc Brake Using Finite Element Analysis,” International Journal of Engineering Research\&Technology (IJERT), vol. 5, pp. 416-419, 2016.

[17] A. Belhocine, "Finite element analysis of automotive disk brake and pad in frictional model contact," International journal of manufacturing, materials, and mechanical engineering (IJMMME), vol. 5, pp. 32-62, 2015, doi: 10.4018/1jmmme.2015100103

[18] S. Gautam, S. Yadav, S. Akhtar, V. Shani, S. Tiwari, D. Yadav, S. Lal, "Finite Element Analysis of Disc Brake Using Ansys Workbench Software," International Journal of Scientific \& Engineering Research, vol. 6, pp. 1954-1959, 2015

[19] N. Liu, Z. Zheng, Y. Wu, X. Kong, H. Ding, "Finite Element Analysis of Drum Brake Assembly," The Italian Association of Chemical Engineering, vol. 46, pp. 1057-1062, 2015, doi: 10.3303/CET1546177

[20]B. Goo, "A study on the contact pressure and thermo-elastic behavior of a brake disc pad by infrared images and finite element analysis," Applied Sciences, vol. 8, no. 9, 2018, doi: 10.3390/app8091639

[21] S. Zhang, Q. Hao, Y. Liu, L. Jin, F. Ma, Z. Sha, D. Yang, "Simulation Study on Friction and Wear Law of Brake Pad in High-Power Disc Brake," Mathematical Problems in Engineering, 2019, doi: $10.1155 / 2019 / 6250694$

[22] G. Riva, F. Varriale, J. Wahlström, "A finite element analysis (FEA) approach to simulate the coefficient of friction of a brake system starting from material friction characterization", Friction, vol. 9, 2020, doi: 10.1007/s40544-020-0397-9

[23] S. Gurumoorthy, S. Grandhi, S. Sridhar, "Brake pad wear prediction using finite element techniques," SAE International, 2021, doi: 10.4271/2021-01-0810

[24] A. Rashid, N. Strömberg, "Thermomechanical simulation of wear and hot bands in a disc brake by adopting an eulerian approach,” Materials Science, pp. 1-10, 2013.

\section{Özgeçmiş}
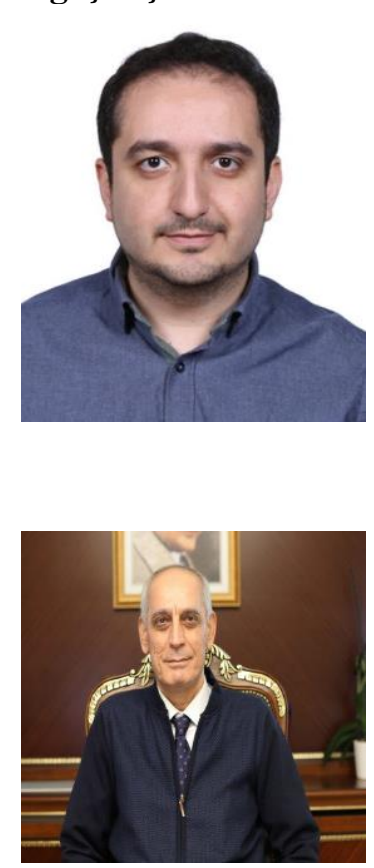

\section{Abdülkadir ÜNAL}

1987 yılında Malatya'da doğdu. Lisans eğitimini Karadeniz Teknik Üniversitesi Makine Mühendisliği Bölümünde tamamladı. Yüksek Lisans eğitimini Marmara Üniversitesi Mekatronik Mühendisliği Bölümünde tamamladı. Halen Marmara Üniversitesi Mekatronik Mühendisliği Bölümü Doktora Programında tez aşamasında öğrenimine devam etmektedir. Türkiye Raylı Sistem Araçları AȘ'de Yeni Projeler Koordinatörü, Hizlı Tren Proje Koordinatörü ve Ar-Ge Daire Başkan Vekili gibi görevlerde yer almıştır. Halen TÜRASAŞ’ta Boji-Pnömatik Müdürü olarak görev yapmaktadır.

E-Posta: abdulkadir.unal @ turasas.gov.tr

\section{Nihat AKKUŞ}

24 Kasım 1964 y1lında doğdu. Lisans eğitimini Marmara Üniversitesi Teknik Eğitim Fakültesi Makine Eğitimi Bölümünde tamamladı. Yüksek Lisans Eğitimini Marmara Üniversitesi Teknik Eğitim Fakültesi Metal Eğitimi Bölümünde tamamladı. Doktora eğitimini, Tokyo Büyükşehir Teknoloji Enstitüsünde tamamladı. Universite de Bourgogne ve Marmara Üniversitesinde öğretim üyesi olarak görev ald1. Halen Gedik Üniversitesinde Rektör olarak görev yapmaktadır. E-Posta: nihat.akkus@ marmara.edu.tr 


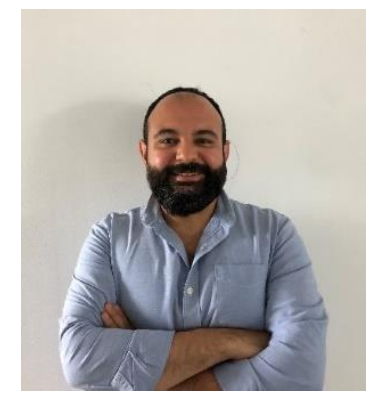

\section{Seyfettin Tolga KANDIL}

1981 yılında Adana doğdu. 2010 yılında Yıldız Teknik Üniversitesi, Makine Mühendisliği Bölümünü tamamladı. Yüksek lisans eğitimini, İstanbul Teknik Üniversitesi, Otomotiv bölümünde sürdürmektedir. 2014 yılında TÜRASAŞ'a atandı 2017-2018 yılları arası Hazırlamalar başmühendisliği görevinde bulundu. Eş zamanlı olarak E23000 elektrikli dizilerin $F$ ağır bakım proje koordinatörlüğünü yürüttü. 2019-2021 yıllarında Ar-Ge Dairesinde Boji başmühendisliği görevinde bulundu. 2021 yılında Teknik Hizmetler Dairesine atand1 ve Boji-Pnömatik Sistemler Müdürlüğünde görevini sürdürmektedir.

\section{Beyanlar:}

E-Posta: tolga.kandil@turasas.gov.tr

Bu makalede bilimsel araştırma ve yayın etiğine uyulmuştur.

Yazarların katkıları: Çalışmaya yazarlar eşit oranda katkı sağlamıştır. 